\title{
Captura de Resíduos Sólidos Drenados em uma Bacia Hidrográfica Urbana
}

\author{
Alessandro Salles da Silva, Geraldo Lopes da Silveira, Delmira Beatriz Wolff e Jussara Cabral Cruz \\ Departamento de Engenharia Sanitária e Ambiental, Centro de Tecnologia, UFSM \\ alessandromardini@gmail.com; geraldo.ufsm@gmail.com; delmirawolff@hotmail.com; jussaracruz@gmail.com
}

Recebido: 09/07/10 - revisado: 21/06/11 - aceito: 17/08/11

\section{RESUMO}

Com o acelerado crescimento populacional verifica-se o aumento na produção de resíduos sólidos, os quais, quando descartados inadequadamente e carreados no sistema de drenagem pluvial, geram conseqüências ambientais como o acúmulo de resíduos nas seções canalizadas da rede pluvial, reduzindo a capacidade de escoamento de condutos, rios e lagos urbanos, e ainda o transporte de poluente agregado a esse material. Assim, conceber estratégias para o monitoramento destes resíduos representa passo importante para buscar soluções visando um melhor gerenciamento de bacias hidrográficas urbanas. Este trabalho teve como objetivo apresentar uma estrutura para a captura dos resíduos sólidos carreados pelo fluxo de água em uma bacia com características urbanas, localizada na região central e totalmente contida na cidade de Santa Maria - RS, a qual deve ser robusta para resistir às intempéries e deve oferecer condições de continuidade ao monitoramento. Além disso, apresenta-se a quantificação e qualificação do resíduo carreado pela drenagem em dez eventos de chuva. Por fim, constatouse que a estrutura implantada foi eficiente na retenção dos resíduos, e que a principal constituição dos resíduos foi matéria orgânica incluindo restos de vegetação, abrangendo $67 \%$ da massa total dos resíduos quantificados, seguidos de plásticos $(14 \%)$.

Palavras-chave: Armadilha para coleta de resíduos, monitoramento dos resíduos, recursos hídricos, resíduos urbanos.

\section{INTRODUÇÃO}

Nas últimas décadas o aumento populacional, o êxodo rural e o avanço tecnológico vêm acarretando o crescimento das cidades, tornando-as grandes centros urbanos. Este crescimento produz uma acelerada urbanização que está aliada ao aumento da produção de resíduos sólidos e ao aumento da impermeabilização das superfícies, originando danos ao meio ambiente urbano quando não gerenciados adequadamente (Neves; Tucci, 2003).

Os fatores que influenciam no carreamento de resíduos sólidos urbanos em sistemas de drenagem, citados por Allison et al. (1998) são: tipo de ocupação do solo: comercial, industrial, residencial e parques; população urbana; práticas de gerenciamento, como serviços de limpeza pública, forma de acondicionamento dos resíduos, regularidade da limpeza e coleta dos resíduos, existência de programas de triagem; programas de sensibilização e educação da população local; período de tempo sem precipitações pluviométricas; características dos eventos de precipitação, tamanho, geometria e localização das bocas de lobo e condutos da rede de microdrenagem; características físicas da bacia hi- drográfica, como tamanho, declividade, características da superfície e vegetação; percentual e tipo de pavimento utilizado, as variações sazonais e intensidade e direção do vento.

Como conseqüências ambientais resultantes do descarte inadequado de resíduos sólidos, Tucci (2002) aponta o acúmulo de resíduos nas seções canalizadas da rede, reduzindo a capacidade de escoamento de condutos, rios e lagos urbanos, e ainda o transporte de poluente agregado a esse material, contaminando as águas pluviais. Armitage e Roseboom (2000) destacam ainda como conseqüências ambientais os aspectos desagradáveis; alto potencial de riscos a saúde humana associado com a putrefação do conteúdo no interior de garrafas e latas, ou organismos patogênicos em seringas descartadas; riscos à fauna aquática; organismos patogênicos ou tóxicos como metais pesados, envenenando a cadeia alimentar de vida aquática e possivelmente atingindo os humanos e custos significativos para o poder público local para conduzir operações de autolimpeza.

Neste contexto, o monitoramento de resíduos sólidos carreados pela drenagem pluvial em zonas urbanas constitui uma técnica importante para buscar soluções visando um melhor gerencia- 
mento de bacias hidrográficas urbanas. Por outro lado, este monitoramento se configura por ser uma atividade perigosa, além de inóspita e de pouca atratividade para a pesquisa devido ao risco de contração de doenças de veiculação hídrica tal como a leptospirose, entre outras. Além disto, a estrutura de monitoramento deve ser robusta o suficiente para resistir às intempéries e as conseqüências de eventual tensão social nos locais onde sejam implantadas. Por fim, deve oferecer condições de continuidade ao monitoramento tal qual uma estação de monitoramento fluviométrico ou pluviométrico.

Diversas metodologias para a coleta de resíduos sólidos têm sido utilizadas, entre as quais, redes em tela de aço instaladas transversalmente ao eixo do curso d'água (Brites et al, 2004), armadilhas metálicas com estrutura basculante (Oliveira et al, 2005), estruturas autolimpantes e SEPT (Side-Entry Pit Trap).

As redes para retenção do material lançado no sistema de drenagem empregado por Brites et al (2004) foram feitas de telas de aço com malha de 70 $\mathrm{mm}$, instaladas transversalmente ao eixo dos rios, para a retenção dos resíduos sólidos transportados. Estas redes de retenção foram fixadas junto a vegetação ribeirinha nas seções de amostra, por meio de tiras de aço galvanizado de $5 \mathrm{~mm}$ de espessura.

As armadilhas metálicas com estrutura basculante empregadas por Oliveira et al, (2005) consistiam em placas orientadoras, sendo que estas direcionavam os resíduos transportados pelo sistema de drenagem para uma gaiola de captação que era basculada com o auxílio de uma talha mecânica e posteriormente esvaziadas, sendo que os resíduos coletados eram dispostos em uma área pavimentada, localizado ao lado da gaiola, onde era realizada a sua classificação e pesagem.

As estruturas autolimpantes eram formuladas para utilizar a pressão da água para empurrar o resíduo, limpando o segregador (tela ou grade), e desviando-o para um local de acumulação, onde a freqüência de limpeza possa ser menor, agindo com mínima perda de carga (Neves, 2006).

A estrutura SEPT (Side-Entry Pit Trap).possui cestas acopladas à entradas de bocasde-lobo, sendo que a água pluvial escoa por uma cesta e o material maior que o tamanho da malha (5-20 $\mathrm{mm})$ é retido. O material fica retido na cesta até a equipe de manutenção remover o material manualmente ou usando um aspirador de grande diâmetro, a cada 4 ou 6 semanas (Allison et al. 1998),.

Este trabalho tem como objetivo apresentar uma nova estrutura para coleta dos resíduos sólidos carreados pelo fluxo de água em uma bacia totalmente urbanizada, localizada na região central e totalmente contida no município de Santa Maria RS.

\section{MATERIAL E MÉTODOS}

\section{Área de estudo}

O trabalho foi desenvolvido junto ao leito de um arroio denominado Esperança, situado em uma bacia hidrográfica de $0,5 \mathrm{~km}^{2}$ com característica urbana situada no município de Santa Maria, na região central do Estado do Rio Grande do Sul, denominada Bacia Escola Urbana - BEU, como mostrado na Figura 1. O Arroio Esperança, seu curso de água principal, possui suas nascentes na parte central da cidade, flui pela vila Valdemar Rodrigues e deságua no Arroio Cadena, que drena a região central do perímetro urbano de Santa Maria. Esta bacia possui áreas com vegetação e áreas com densa ocupação urbana.

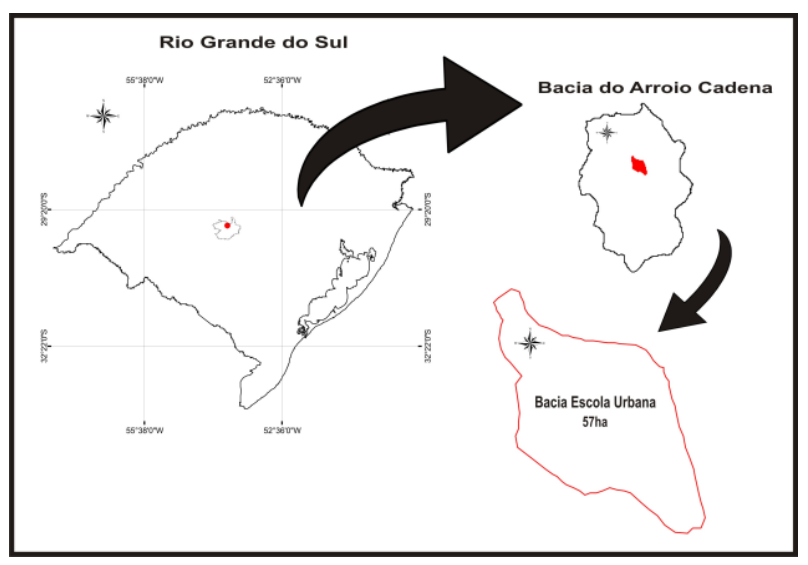

Figura 1 - Localização da bacia escola urbana

\section{Estrutura de monitoramento dos resíduos sólidos drenados (RSDREN)}

Para reter os resíduos sólidos carreados durante os eventos de precipitação, seja por escoamento superficial ou lançados diretamente na rede de drenagem, foi projetada e instalada a campo uma armadilha, que foi fixada em um medidor de vazão, tipo calha Parshall de fundo plano, construído em trecho retilíneo do arroio e próximo ao seu exutório junto ao Arroio Cadena Esta estrutura de coleta 


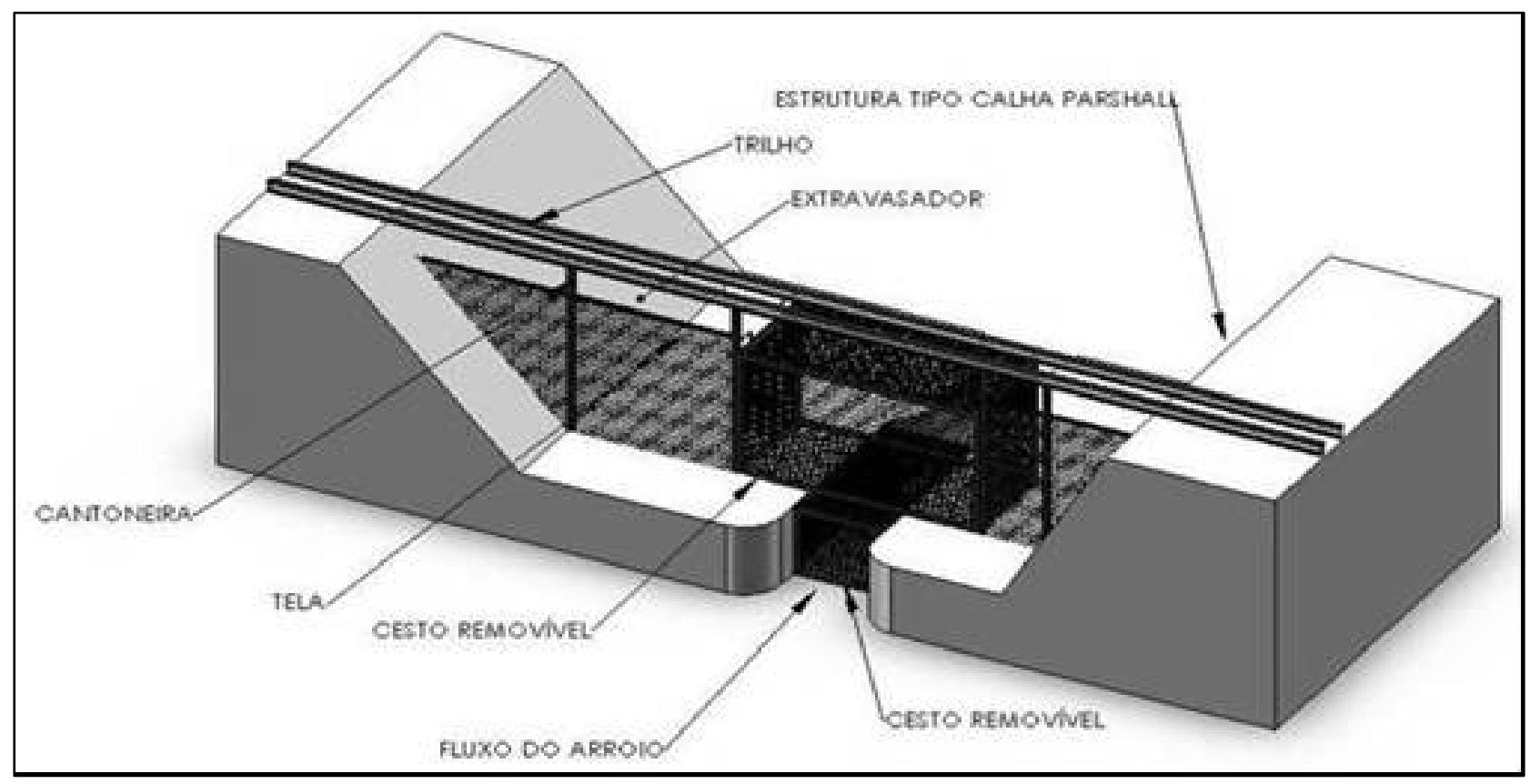

Figura 2 - Perfil isométrico da estrutura de coleta

possuia uma parte fixa nas laterais e uma parte móvel ao centro do arroio onde foram instalados cestos removíveis. Foi projetada em forma retangular com dimensões do cesto maior de $2,0 \times 1,1 \times 0,9 \mathrm{~m}$, cesto menor $0,6 \times 0,7 \times 1,4 \mathrm{~m}$ e com laterais triangulares fixas, que acompanham o perfil dos taludes. A estrutura móvel continha um dispositivo de transbordo de $0,30 \mathrm{~m}$ acima dos $1,7 \mathrm{~m}$ de altura (da base do cesto menor até o final do cesto maior), para possíveis situações de represamento evitando-se, assim, que as ondas de cheia causassem a obstrução parcial do canal com risco de inundações à montante da seção.

Na Figura 2, apresenta-se um desenho esquemático di estrutura de coleta em perfil isométrico com os nomes dos componentes utilizados para a execução do projeto.

Na Figura 3 tem-se o esquema da estrutura de coleta de resíduos em vista frontal, com as respectivas medidas dos componentes que foram utilizados para a implantação do projeto, e em planta, com as respectivas medidas da estrutura de coleta, bem como a localização e medidas do piso pavimentado, que foi construído no terreno ao lado da calha Parshall, com a finalidade de depositar os resíduos retirados da estrutura coletora, a fim de escoar o excesso de umidade destes resíduos.
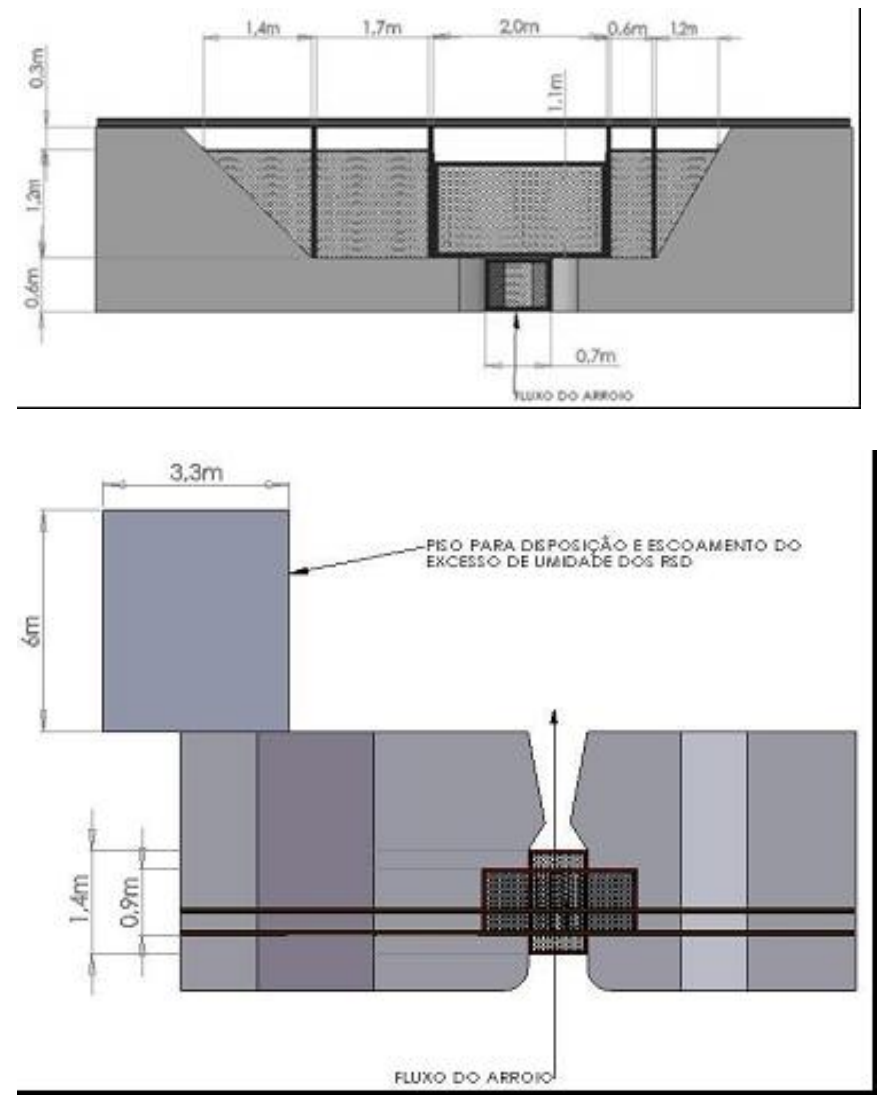

Figura 3 - Esquema da estrutura de coleta de resíduos 
Na Figura 4 é mostrada uma foto da estrutura de captura de resíduos sólidos na drenagem instalada junto à calha Parshall, onde se pode perceber a vegetação existente às margens do arroio Esperança.

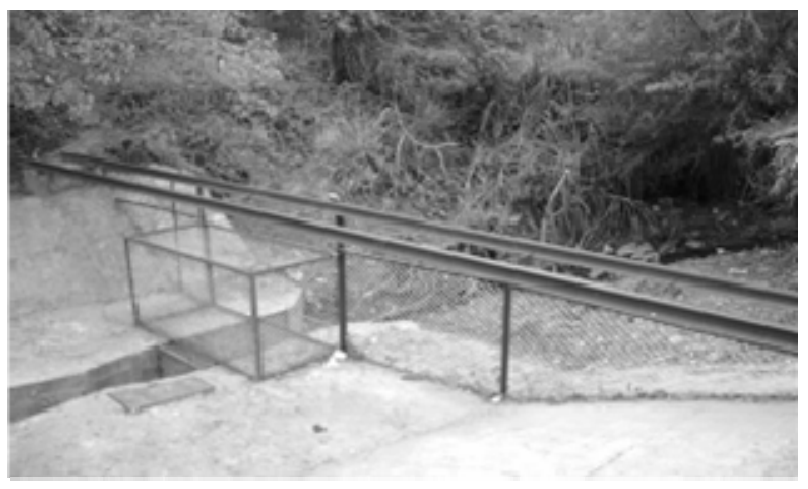

Figura 4 - Foto da estrutura de coleta instalada.

\section{Qualificação e quantificação dos resíduos retidos}

Tabela 1 - Resíduos sólidos de classe inorgânica e o padrão de cores

\begin{tabular}{cc}
\hline Classe Inorgânica & Padrão de cores* \\
\hline $\begin{array}{c}\text { Plásticos (sacolas, garrafas, reci- } \\
\text { pientes, sacolas de leite e outros). } \\
\text { Metais (chapas, latas, e outros). }\end{array}$ & Vermelho \\
$\begin{array}{c}\text { Vidros (garrafas, copos e lâmpa- } \\
\text { das). }\end{array}$ & Amarelo \\
$\begin{array}{c}\text { Tecidos e isopor. } \\
\text { Papéis (papelão, papel branco e } \\
\text { outros). } \\
\text { Pneus e borrachas. }\end{array}$ & Verde B \\
$\begin{array}{c}\text { Resíduos perigosos. } \\
\text { Resíduos ambulatoriais, de servi- } \\
\text { ços de saúde e animais mortos. } \\
\text { Outros }\end{array}$ & Preto B \\
\hline
\end{tabular}

* segundo a Resolução do CONAMA n. ${ }^{\circ} 275$ de 25 de abril de 2001

Os resíduos retidos eram retirados da estrutura e depositados no piso pavimentado para a retirada do excesso de umidade destes. Após, era feita a separação gravimétrica dos resíduos e sua classificação em resíduos orgânicos e inorgânicos, bem como sua identificação e registro de acordo com suas características, conforme o padrão de cores da Resolu- ção do CONAMA n. 275 de 25 de abril de 2001. Para efetuar a pesagem de todo o resíduo capturado na armadilha utilizava-se uma balança de precisão com capacidade de $100 \mathrm{~kg}$. Os valores de cada campanha de qualificação e quantificação dos resíduos sólidos são mostrados nas Tabelas 1 e 2 ..

Tabela 2 - Resíduos sólidos de classe orgânica e o padrão de cores

\begin{tabular}{ll}
\hline Classe Orgânica & Padrão de cores* \\
\hline $\begin{array}{l}\text { Restos de alimentos. } \\
\text { Restos de vegetação (folhas, } \\
\text { galhos, cascas, raízes e outros). }\end{array}$ & Marrom A \\
Madeira processada. & Parrom B \\
\hline
\end{tabular}

* segundo a Resolução do CONAMA n. ${ }^{\circ} 275$ de 25 de abril de 2001

\section{RESULTADOS}

\section{Estrutura de monitoramento dos Resíduos Sólidos Drenados (RSDREN)}

Após os ajustes operacionais, a estrutura demonstrou efetividade aos objetivos delineados de robustez e permanência no local, além de reter os resíduos em cada evento de precipitação, permitindo a sua qualificação e quantificação. Na figura 5 são mostrados os resíduos sólidos retidos na estrutura após um evento de precipitação.

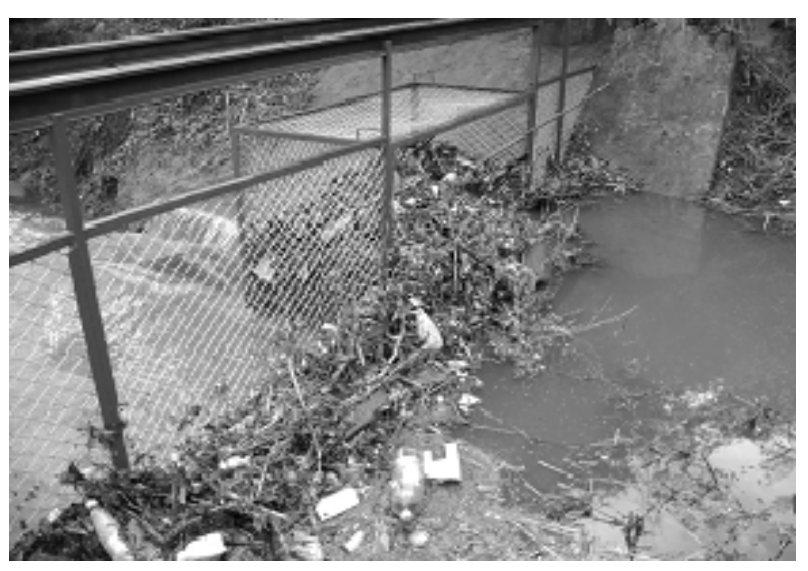

Figura 5 - Resíduos sólidos retidos na estrutura

Durante o período de um ano foram monitorados dez eventos de precipitação cujos resultados da quantificação são apresentados na tabela 3. 


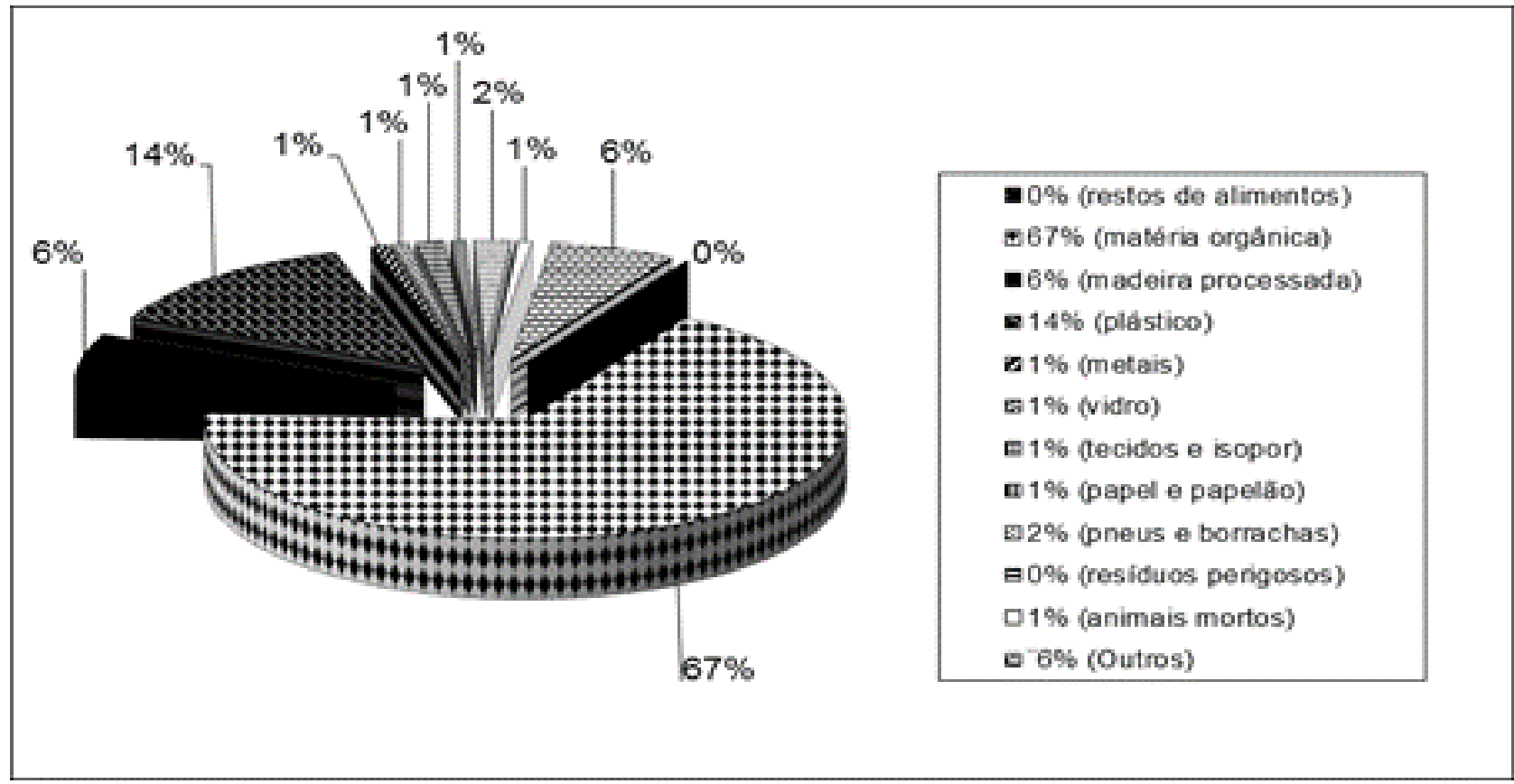

Figura 6 - Classificação de resíduos coletados na bacia em estudo

Tabela 3 - Eventos de precipitação monitorados

\begin{tabular}{c|c|c}
\hline Eventos & $\begin{array}{c}\text { Precipitação } \\
\text { (mm) }\end{array}$ & $\begin{array}{c}\text { Quantidade } \\
\text { resíduos } \\
\text { retidos (kg) }\end{array}$ \\
\hline 1 & 7 & 26 \\
\hline 2 & 16,2 & 120 \\
\hline 3 & 21 & 154 \\
\hline 4 & 71,5 & 385 \\
\hline 5 & 33 & 296 \\
\hline 6 & 8,3 & 166 \\
\hline 7 & 47 & 280 \\
\hline 8 & 4,7 & 60,6 \\
\hline 9 & 53 & 503 \\
\hline 10 & 29 & 227 \\
\hline
\end{tabular}

As maiores quantidades de resíduos foram observadas nos eventos de maior intensidade, sendo $385 \mathrm{~kg}$ para um evento de $71,5 \mathrm{~mm}$ e o valor máximo de $503 \mathrm{~kg}$ para um evento de $53 \mathrm{~mm}$. A menor quantidade foi observada em um evento de $7 \mathrm{~mm}$.

Também se constatou que durante os eventos de precipitação intensa, uma elevada quantidade de resíduos sólidos ficou prensada nos cestos coletores e nas telas laterais. Isto requereu atenção constante da equipe após as precipitações de alta intensidade para a remoção imediata do material retido na estrutura de coleta de resíduos no arroio.

\section{Qualificação e quantificação dos resíduos retidos}

Na Figura 6 é mostrado a qualificação dos resíduos acumulados na seção de monitoramento no arroio Esperança,. de acordo com a classificação de cores da resolução CONAMA 257/2001. . É importante ressaltar que o monitoramento ocorreu em uma bacia que envolve a região central da cidade contemplada com sistema de coleta de resíduos sólidos e serviços de limpeza urbana, e uma vila urbana, constituída por algumas residências em área de invasão. Eberhardt et al (2007) realizaram um diagnóstico sócioambiental junto à comunidade em torno do Arroio Esperança, por meio de aplicação de questionários, tomando uma amostragem de 100 residências, das quais $64,0 \%$ afirmaram que seus resíduos sólidos são colocados na lixeira para coleta urbana, 23,5\%; se destina aos catadores, e que $12,5 \%$. encaminham para outros destinos,

A matéria orgânica foi o material mais abundante com $67 \%$ da massa total, sendo composto de folhas, caules, raízes e galhos de árvores, devido à vegetação de grande porte existente em algumas partes das margens do corpo d'água. Já a madeira processada representou $6 \%$ do material coletado, fato esse que se deu pela intensa ocupação da região do entorno do arroio. Esses resultado estão coerentes com os obtidos por Brites et al (2004) que encontraram resultados semelhantes na avaliação de 
resíduos sólidos drenados na bacia hidrográfica do arroio Cancela, situado também na cidade de Santa Maria - RS, sendo que o material mais abundante verificado foi a matéria orgânica, com $80 \%$.

O material plástico representou $14 \%$ do volume retido, sendo constituído principalmente por sacolas de supermercado e embalagens de doces e salgados (balas, picolés e salgadinhos). Como a BEU abrange o centro da cidade de Santa Maria-RS, pode ocorrer o lançamento deste tipo de resíduo na rede de drenagem pluvial, os quais podem ser arrastados até o arroio estudado. Schiavo (2001, p.10) defende que o ato de jogar ou "deixar cair" coisas na via pública não é por compulsão, mas advém da cultura paternalista, de que o indivíduo não é responsável por si próprio e transfere o dever a terceiros. Neste caso, o dever de deixar a cidade limpa e zelar pela natureza passa a ser da prefeitura, da sociedade, e não do indivíduo, ou seja, é uma tentativa de diminuir a sua própria responsabilidade.

Salienta-se que, devido ao tipo de cobertura vegetal nas margens do corpo d'água, parte do material, principalmente sacolas plásticas, permaneciam retidos ao longo de seu percurso, não alcançando os cestos coletores de resíduos.

A massa de metais (Amarelo) e vidros (Verde A) encontrada foi de $1 \%$, respectivamente. Os metais compostos por latas e chapas não apareceram em grande quantidade, devido ao seu elevado valor agregado para a reciclagem. Os resíduos constituídos por metais que foram coletados para pesagem são resíduos provavelmente gerados por oficinas mecânicas e materiais com componentes metálicos descartados pela população ribeirinha que era desmembrado na hora da classificação.

O material que apresentou uma quantidade significativa na BEU, considerando seu baixo peso e grande volume, foi o isopor, seguido dos poucos tecidos encontrados, juntamente com alguns pedaços de colchões (Verde B), com $1 \%$ da massa total, devido à densidade populacional da região relacionado ao consumo de eletrodomésticos e ao descarte de roupas usadas que são jogadas no arroio.

Os papéis (Azul) não tiveram uma representação muito significativa $(1 \%)$, sendo constituído principalmente por caixas de leite longa vida, os papéis em folha e de embalagens comuns foram pouco observados, provavelmente por se dissolverem em contato com a água e se misturarem com a matéria orgânica.

A classe Outros apresentou $6 \%$ da massa total quantificada, sendo os materiais na sua maioria constituídos de fraldas descartáveis, calçados, guarda-chuvas, e materiais não identificados.
Em relação aos materiais potencialmente recicláveis gerados nos domicílios e constituídos por materiais como plástico, papel, papelão, metal, vidro, trapos, borracha e madeira, obteve-se o percentual de $27 \%$, sendo que, de acordo com Philippi Jr. (1999), a média brasileira é de $31,3 \%$.

\section{CONCLUSÕES}

Com base nos resultados obtidos no monitoramento dos resíduos sólidos na bacia em estudo, chegou-se às seguintes conclusões:

- que a estrutura de coleta dos RSDREN atendeu aos objetivos a que se propunha - de monitorar quantitativamente e qualitativamente - os resíduos sólidos carreados pela drenagem além de produzir informações confiáveis, em apoio aos gestores municipais.

- que os montantes de resíduos carreados pela drenagem e monitorados pela estrutura de coleta apresentaram valores máximos de $503 \mathrm{~kg}$, a despeito da infra-estrutura da região, que possui um sistema de coleta de resíduos sólidos em toda a região central e parte da vila. Isto certamente traz informações e subsídios para a reflexão dos gestores municipais.

- relativo a operacionalidade dos sistema de monitoramento em si, conclui-se que para manter este serviço é necessário, devido ao montante de resíduos coletados, contar com a força de trabalho de quatro operadores para a remoção dos cestos cheios e sua condução até a área de secagem dos resíduos sólidos.

- observa-se que a presença de plástico no arroio é um grande obstáculo à drenagem devido ao grande consumo deste pela população e, devido à sua impermeabilidade, pode obstruir as estruturas de drenagem, o que poderá provocar inundações. Além disso, conduz a uma poluição visual e um aspecto desagradável ao local.

- o material isopor foi verificado em grande quantidade, apesar do pouco peso quantificado por ser um material leve.

- a matéria orgânica em grande quantidade ocorre devido às condições naturais da bacia em alguns trechos do arroio. 
- a madeira processada obteve o percentual de $6 \%$ e isto ocorreu devido ao descarte do material pela população urbana do local. Já metais e vidros obtiveram um baixo percentual, assim como os papéis. A classe "outros" apresentou um percentual de $6 \%$ diante de curiosidades como calçados, fraldas descartáveis e guarda-chuvas. Ademais, considerável quantidade de animais mortos foi detectada.

- É importante salientar a parcela total de materiais potencialmente recicláveis, $27 \%$, que foram descartados no leito do riacho. Isto denota significativa ausência de sensibilização ambiental. Apesar da disseminação de informações acerca da reciclagem de materiais, ainda há uma grande falta de comprometimento e hábitos pela população.

\section{AGRADECIMENTOS}

Os autores agradecem ao CNPq pelo financiamento da pesquisa e bolsa de estudo.

\section{REFERÊNCIAS}

ALLISON, R.A. et al. 1998. From roads to rivers - Gross pollutant removal from urban waterways, Research Report for the Cooperative Research Centre for Catchment Hydrology, Australia, $98 \mathrm{f}$.

ARMITAGE, N; ROOSEBOOM, A., 2000. The removal of urban litter from stormwater counduits and streams. Paper 1 - The quantities involved and catchments litter management options. Water S.A. $n^{\circ} 2$ vol. 26.

BRITES, A. P. Z. et al, 2004. Avaliação dos Resíduos Sólidos Veiculados em Sistemas de Drenagem Urbana. In: IV Simpósio Internacional de Qualidade Ambiental, Porto Alegre. v. 1. p. 1-8.

EBERHARDT et al , 2007. Diagnóstico socioambiental da comunidade da bacia escola hidrográfica urbana, Santa Maria - RS Disciplinaruma. Scientia. Série: Ciências Naturais e Tecnológicas, v. 8, n. 1, p. 5568.

NEVES, M. G. F. P.; TUCCI, C. E. M. G., 2003 Gerenciamento Integrado em Drenagem Urbana: Quantificação e Controle de Resíduos Sólidos. In: XV Simpósio Brasileiro de Recursos Hídricos / ABRH, Anais. Curitiba,

OLIVEIRA, A. L. ; SCHETTINI, E. ; SILVEIRA, A. L. L. 2005,. Estrutura para coleta de resíduos sólidos em arroio urbano. In: I Simpósio de Recursos Hídricos do Sul RS/PR/SC, Santa Maria/RS. Anais do I Simpósio de Recursos Hídricos do Sul - RS/PR/SC. Santa Maria : $A B R H, 2005$. v. 1. p. 1-10.

PHILIPPI JUNIOR, A., 1999. Agenda 21 e resíduos sólidos. Seminário Sobre Resíduos Sólidos. Anais, São Paulo: Associação Brasileira de Geologia de Engenharia.. p. 15-22.

SHIAVO, S. 2001. Irresponsável ato de sujar o ambiente. Pioneiro. Caxias do Sul, jan.

TUCCI, C. E. M. 2002. Gerenciamento da Drenagem Urbana. Revista Brasileira de Recursos Hídricos. Volume 7, n. 1. ABRH. Jan/Mar.

\section{Retention of Drained Solid Wastes in an Urban river Basin}

\section{ABSTRACT}

The production of solid wastes has increased due to the rapid growth of population. When the waste is disposed of inappropriately and carried into the storm drainage system, there are environmental consequences such as the accumulation of wastes in the storm sewerage system, reducing the runoff capacity of conduits and urban rivers and lakes, and pollutants are transported in this material. Therefore it is important to create strategies to monitor these wastes, with better management of urban river basins. The purpose of this work was to present a structure to capture the solid wastes carried by the water flow in a basin with urban characteristics, located in the central region and completely contained in the city of Santa Maria, state of Rio Grande do Sul, Brazil. It must be robust to resist weather conditions and it must allow continuous monitoring. In addition the wastes carried by drainage in ten rainfall events are quantified and qualified. Finally, it was found that the structure implemented was efficient to retain the wastes, and that they were mainly comprised of organic matter including plant litter which made up $67 \%$ of the total mass of quantified wastes, followed by plastics (14\%). Key-words: Waste traps, waste monitoring, water resources, urban wastes 